\title{
Iron deficiency anemia as a risk factor for the first episode of febrile seizure
}

\author{
Saleem M. ${ }^{1}$, Ahmed Siddique A. ${ }^{2 *}$ \\ DOI: https://doi.org/10.17511/ijpr.2020.i02.08
}

1 Mohammed Abdul Saleem, Assistant Professor, Department of Paediatrics, Gandhi Medical College, Secunderabad, Telangana, India.

2* Abrar Ahmed Siddique, Assistant Professor, Department of Paediatrics, Niloufer Hospital, Hyderabad, Telangana, India.

Background: Febrile seizures are defined as an event in neurologically healthy infants and children between 6 months and 5 years of age, associated with fever $>38^{\circ} \mathrm{C}$ rectal temperature but without evidence of intracranial infection as a defined cause and with no history of prior afebrile seizures. Objective: This study is aimed at evaluating the association between iron deficiency anemia and febrile seizures. Design: A prospective hospital-based study, carried out in the Department of Pediatrics, Gandhi Hospital, Secunderabad. Duration: October 2014 to November 2015. Setting: Department of Pediatrics, Gandhi Hospital, Secunderabad. Participants: 50 cases of the first episode of simple febrile seizure in the age group of 1 year to 5 years admitted to the pediatric ward. A control group was selected from age and sex-matched children admitted with febrile illness but without a seizure. Methods: Cases were patients with typical febrile convulsions between 1 year to 5 years (AAP clinical practice guidelines). In all cases, detailed clinical history, anthropometry, a clinical sign of iron deficiency, CNS examination was done. Hematological investigations including CBC, PBF, Red cell indices, Serum Iron, Serum Ferritin and Serum TIBC level were done. Results: Incidence of anemia among case group subjects was $88 \%$ whereas the same in the control group was 24\%. Mean RDW and TIBC levels in cases were significantly higher as compared to that in controls. MCV, Mean Serum Ferritin and Serum Iron levels in cases were significantly lower as compared to that in controls. Conclusion: The findings suggest that a considerable percentage of children having febrile seizures suffer from iron-deficiency anemia and low serum iron. This means the low serum iron and the presence of anemia can serve as a reinforcing factor for febrile seizures in children.

Keywords: Febrile convulsions, Iron-deficiency Anemia, Children

\section{Corresponding Author}

Abrar Ahmed Siddique, Assistant Professor, Department of Paediatrics, Niloufer Hospital, Hyderabad, Telangana, India. Email: drabrarniloufer@gmail.com
How to Cite this Article To Browse Saleem MA, Siddique AA. Iron deficiency anemia as a risk factor for the first episode of febrile seizure. Pediatric Rev Int J Pediatr Res. 2020;7(2):93-96. Available From https://pediatrics.medresearch.in/index.php/ijpr/arti cle/view/578

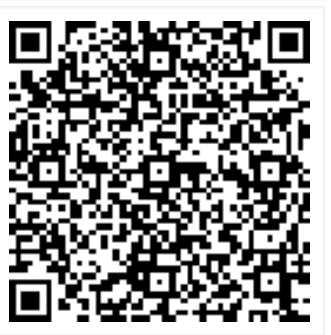

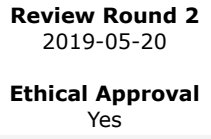

Review Round 3

Accepted 2019-05-25

Plagiarism $\mathbf{X}$-checker $7 \%$ 


\section{Introduction}

Febrile seizure (FS) is the most common type of childhood seizure, which occurs in $2-5 \%$ of neurologically healthy children. FS is defined as a seizure associated with a febrile illness in the absence of central nervous system (CNS) infections or acute electrolyte abnormalities in 6-60month old children without previous afebrile seizures [1]. FS is further classified as simple and complex types. Complex FS is defined as a seizure lasting more than $15 \mathrm{~min}$, and recurring within $24 \mathrm{~h}$ or focal seizure. Iron deficiency is one of the most frequent micronutrient deficiencies and affects at least onethird of the population of the world [2]. Anemia is the most common clinical manifestation of iron deficiency, but other organs and systems may also be affected. Cognitive dysfunction, psychomotor retardation, behavioral impairments, pica, breathholding spells, restless leg syndrome, and thrombosis could be associated with iron deficiency $[3,4]$. Effect of iron deficiency in the developing brain and mechanisms such as altered development of hippocampus neurons, impairment of energy metabolism, delayed maturation of myelin, slowed visual and auditory evoked potentials and alterations in synaptic neurotransmitter systems including norepinephrine, dopamine, glutamate, $\mathrm{Y}^{-}$ aminobutyric acid, and serotonin may be responsible for these symptoms [6]. On the other hand, fever may aggravate the negative effects of iron deficiency on the brain [7]. The relationship between iron deficiency anemia (IDA) and FS has been evaluated in several studies with conflicting results. The aim of this case-control study was to evaluate the relation of Iron Deficiency Anemia with the first episode of Febrile Seizure. A family history of convulsions; maternal smoking; and alcohol consumption during pregnancy have been associated with febrile seizures, but the risk factors remain largely unknown. Iron is involved in the metabolism of several neurotransmitters, and monoamine and aldehyde oxidase are reduced in iron deficiency anemia, which is common during the second and the third year of life and has been associated with behavioral and developmental disturbances. Thus, it can be investigated that the association between iron deficiency anemia and febrile seizures by a case-control study.

\section{Materials and Methods}

Place of Study: Department of Pediatrics, Gandhi Hospital, Secunderabad.
Type of Study: This was a prospective hospitalbased study.

Sample collection: Cases $(n=50)$ were patients with typical febrile convulsions between 1 year to 5 years (AAP clinical practice guidelines). A control group $(n=50)$ was selected from age and sexmatched children admitted with febrile illness but without a seizure. Hematological investigations include Haemoglobin, MCV, MCH, RDW, Serum Ferritin, Serum Iron, TIBC and Peripheral blood smear. Anthropometrical data collection includes weight, recorded on an electronic weighing scale; Measurement of length and height using infantometer and stadiometer respectively; Head circumference was measured using a plastic tape measure by cross tape method; IAP weight for age classification was used to grade protein-energy malnutrition.

\section{Sampling methods: Consecutive sampling}

\section{Inclusion criteria}

- Age between 1 year to 5 years

- The temperature of 38 degree Celsius (100.4 o F ) or higher

- Not the result of central nervous system infection or any Metabolic imbalance.

- Occur in the absence of a history of prior afebrile seizure.

- Primarily generalized, usually tonic-clonic.

- Lasting for a maximum of $15 \mathrm{~min}$.

- Not recurrent within a 24 hrs period.

\section{Exclusion criteria}

- Children with neurological infection.

- Children with developmental delay.

- Children on iron therapy.

- Children with previous febrile/afebrile seizure.

Statistical methods: Statistical analysis was done using appropriate statistical software.

\section{Results}

Distribution of cases according to hemoglobin levels

Table-1: Distribution of cases according to hemoglobin levels.

\begin{tabular}{|c|c|c|}
\hline Haemoglobin Level $(\mathrm{gm} / \mathrm{dl})$ & Cases & \multicolumn{1}{c|}{ Controls } \\
\hline No anemia $(\geq 11 \mathrm{gm} / \mathrm{dl})$ & $6(12 \%)$ & $38(76 \%)$ \\
\hline
\end{tabular}




\begin{tabular}{|l|l|l|}
\hline Anemia & $12(24 \%)$ & $5(10 \%)$ \\
\hline Mild anemia $(10-10.9 \mathrm{gm} / \mathrm{dl})$ & $30(60 \%)$ & $5(10 \%)$ \\
\hline Moderate anemia $(7-7.9 \mathrm{gm} / \mathrm{dl})$ & $2(4 \%)$ & $2(4 \%)$ \\
\hline Severe anemia $(<7 \mathrm{gm} / \mathrm{dl})$ &
\end{tabular}

Table 1 shows that $88 \%(n=44)$ children had $\mathrm{Hb}$ $<11 \mathrm{gm} / \mathrm{dl}$ from the case group as compared to $24 \%(n=12)$ in control group with significant $p$-value $(p<0.01)$. The proportion of cases with anemia was significantly higher as compared to that of controls $(p=0.013)$.

\section{Hematological Parameters}

Table-2: Hematological parameters.

\begin{tabular}{|l|l|l|l|l|l|}
\hline \multirow{2}{*}{ Parameters } & \multicolumn{2}{c|}{ Cases } & \multicolumn{2}{c|}{ Controls } & \multirow{2}{*}{ P-Value } \\
\cline { 2 - 5 } & Mean & S.D. & Mean & S.D. & \\
\hline $\mathrm{Hb}(\mathrm{gm} / \mathrm{dl})$ & 9.10 & 1.65 & 10.06 & 1.66 & $<0.01$ \\
\hline $\mathrm{MCV}(\mathrm{fl})$ & 67.89 & 15.32 & 17.65 & 9.96 & $<0.04$ \\
\hline $\mathrm{MCH}(\mathrm{pg})$ & 21.98 & 5.11 & 24.80 & 5.77 & 0.063 \\
\hline $\mathrm{RDW}$ & 17.99 & 6.78 & 16.19 & 2.34 & $<0.04$ \\
\hline
\end{tabular}

Table 2 shows, mean hemoglobin level and MCV in cases were significantly lower as compared to that in controls ( $p<0.04$ ). RDW value is significantly higher in cases as compared to control ( $p<0.04)$. No significant difference between the two groups was observed with respect to mean $\mathrm{MCH}$ levels ( $p$ $>0.04$ ).

\section{Level of Iron Metabolic Markers in Cases and Controls}

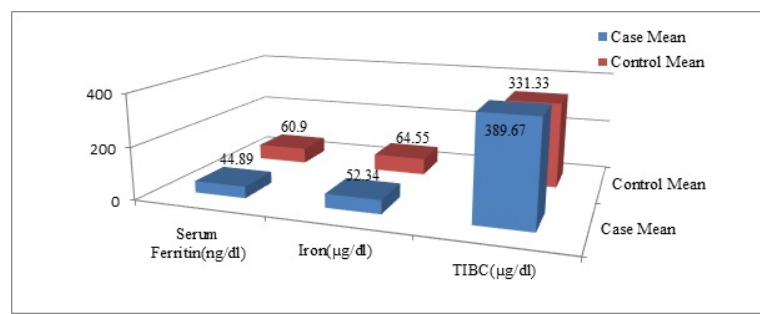

Fig-1: Mean level of iron metabolic markers in cases and controls.

Figure 1 shows serum ferritin and serum iron levels in cases were significantly lower as compared to that in controls ( $p<0.01$ ). TIBC value is significantly higher in cases as compared to control ( $p<0.01)$.

\section{Discussion}

A total of 100 subjects were included in the study. The case group comprised 50 children admitted with the first episode of simple febrile seizure and 50 children in the control group of the matched agegender with febrile illness but without seizures and without iron supplements.
In the present study, the majority of subjects in both groups were males. Sex analysis reveals that $64 \%$ were males and $36 \%$ females in the case group. Leela Kumari et al [8] also reported $53 \%$ of male children in their study. In the present study, characteristics studied were temperature, weight $(\mathrm{Kg})$, height $(\mathrm{Cm})$, nutritional status among which mean temperature was found to have a difference between cases and control but was not statistically significant ( $p$-value $=0.412$ ). This is in accordance to study by Modaresi $M$ et al [9], Vaswani et al [10] and Daoud et al [11] who although reported a higher incidence of high temperature in case group but it was not statically significant. The incidence of anemia was higher among cases as compared to controls. This difference was statistically significant $(p<0.01)$. Other workers of the field as Derakhshanfar et al [12] and Modaresi $M$ et al also reported a statistically significant difference from the control group. The iron status components were measured ( $\mathrm{Hb}, \mathrm{MCV}, \mathrm{MCH}, \mathrm{RDW}$, serum iron, ferritin, and TIBC) among cases and controls. In the present study, it was found that the mean ferritin and serum iron levels in the FS group were significantly lower than the corresponding levels in the control group $(p<0.01)$. Daoud et al reported that the mean level of ferritin in cases with first febrile seizure is significantly lower than that in a control group. Pisacane et al [13] compared the levels of serum iron among controls and patients with FS, and they reported that iron deficiency anemia is significantly more frequent among the cases than among the controls.

\section{Conclusions}

The findings suggest that a considerable percentage of children having febrile seizures suffer from irondeficiency anemia and low serum iron.

\section{What does the study add to the existing knowledge?}

The outcomes from the current study can lay the foundations of the theory that the low serum iron and the presence of anemia can serve as a reinforcing factor for febrile seizure in children.

\section{Author's contribution}

Dr. Mohammed Abdul Saleem: Concept, study design, Dr. Abrar Ahmed Siddique: Statistical analysis, manuscript preparation 


\section{Reference}

01. Shinnar S. Febrile Seizures and Mesial Temporal Sclerosis. Epilepsy Curr. 2003;3(4)115-118. doi: 10.1046\%2Fj.1535-7597.2003.03401.x [Crossref] [PubMed][Google Scholar]

02. Van der Berg BJ, Yerushalmy J. Studies on convulsive disorders in young children, I- Incidence of febrile and nonfebrile convulsions by age and other factors. Pediatr Res. 1969;3;298-304. [Crossref][PubMed][Google Scholar]

03. Wallace SJ. They don't do very well. Pediatr. 1980;65(3)678-679. [Crossref][PubMed][Google Scholar]

04. Mathai KV, Dunn DP, Kurland LT, Reeder FA. Convulsive disorders in the Mariana Islands. Epilepsia. 1968;9(2)77-85. doi: 10.1111/j.1528-115 7.1968.tb05130.x[Crossref][PubMed][Google Scholar]

05. Stanhope JM, Brody JA, Brink E, Morris CE. Convulsions among the Chamorro people of Guam, Mariana Islands- II, Febrile convulsions. Am J of Epidemiol. 1972;95(3)299-304. doi: 10.1093/oxford journals.aje.a121397 [Crossref][PubMed][Google Scholar]

06. Tsuboi T. Epidemiology of febrile and afebrile convulsions in children in Japan. Neurol. 1984;34(2)175-181. doi: 10.1212/WNL.34.2.175 [Crossref][PubMed][Google Scholar]

07. Berg AT, Shinnar S. The contributions of epidemiology to the understanding of childhood seizures and epilepsy. J Child Neurol. 1994;9(2)1926. [Crossref][PubMed][Google Scholar]

08. Kumari PL, Nair MK, Nair SM, Kailas L, Geetha S. Iron deficiency as a risk factor for simple febrile seizures-a case control study. Indian Pediatr. 2012;49(1)17-19. doi: 10.1007/s13312-012-00086 [Crossref][PubMed][Google Scholar]

09. Modaresi M, Mahmoudian T, Yaghini O, Kelishadi $R$, Golestani $H$, Tavasoli $A$, et al. Is Iron Insufficiency Associated With Febrile Seizure?- Experience in an Iranian Hospital. J Compr Ped. 2012;3(1)21-24. doi: 10.17795/compreped-6946 [Crossref][PubMed] [Google Scholar]
10. Vaswani RK, Dharaskar PG, Kulkarni S, Ghosh K. Iron deficiency as a risk factor for first febrile seizure. Indian Pediatr. 2010;47(5)437-439. doi: 10.1007/s13312-010-0080-8 [Crossref][PubMed] [Google Scholar]

11. Daoud AS, Batieha A, Abu-Ekteish F, Gharaibeh $\mathrm{N}$, Ajlouni S, Hijazi S. Iron status- a possible risk factor for the first febrile seizure. Epilepsia. 2002;43(7)740-743. doi: 10.1046/j.15281157.2002.32501.x [Crossref][PubMed][Google Scholar]

12. Derakhshanfar $H$, Abaskhanian $A$, Alimohammadi $H$, ModanlooKordi $M$. Association between iron deficiency anemia and febrile seizure in children. Med Glas (Zenica). 2012;9(2)239-242. [Crossref][PubMed][Google Scholar]

13. Pisacane A, Sansone $R$, Impagliazzo N, Coppola $A$, Rolando P, D'Apuzzo A, et al. Iron deficiency anaemia and febrile convulsions- case-control study in children under 2 years. BMJ. 996;313(7053)343. doi: 10.1136\%2Fbmj.313.7053.343 [Crossref] [PubMed][Google Scholar] 